\title{
BMJ Open Are the needs of people with multiple long-term conditions being met? Evidence from the 2018 General Practice Patient Survey
}

\author{
Lucina Rolewicz (1) , Eilís Keeble (1) , Charlotte Paddison (1) , Sarah Scobie
}

To cite: Rolewicz L, Keeble E, Paddison C, et al. Are the needs of people with multiple long-term conditions being met? Evidence from the 2018 General Practice Patient Survey. BMJ Open 2020;10:e041569. doi:10.1136/ bmjopen-2020-041569

- Prepublication history and additional material for this paper are available online. To view these files, please visit the journal online (http://dx.doi. org/10.1136/bmjopen-2017018243).

Received 11 June 2020 Revised 28 October 2020 Accepted 29 0ctober 2020

\section{Check for updates}

(C) Author(s) (or their employer(s)) 2020. Re-use permitted under CC BY-NC. No commercial re-use. See rights and permissions. Published by BMJ.

Research \& Policy Team, Nuffield Trust, London, UK

\section{Correspondence to} Lucina Rolewicz; lucina.rolewicz@nuffieldtrust. org.uk

\section{ABSTRACT}

Objectives To investigate individual, practice and area level variation in patient-reported unmet need among those with long-term conditions, in the context of general practice (GP) appointments and support from communitybased services in England.

Design Cross-sectional study using data from 199150 survey responses.

Setting Primary care and community-based services. Participants Respondents to the 2018 English General Practice Patient Survey with at least one long-term condition.

Primary and secondary outcome measures The primary outcomes were the levels of unmet need in GP and local services among patients with multiple long-term conditions. Secondary outcomes were the proportion of variation explained by practice and area-level factors.

Results There was no relationship between needs being fully met in patients' last practice appointment and number of long-term conditions once sociodemographic characteristics and health status were taken into account (5+conditions-0R=1.04, 95\% $\mathrm{Cl} 0.99$ to 1.09), but there was a relationship for having enough support from local services to manage conditions $(5+$ conditions $-0 R=0.84$, $95 \% \mathrm{Cl} 0.80$ to 0.88 ). Patients with multimorbidity that were younger, non-white or frail were less likely to have their needs fully met, both in GP and from local services. Differences between practices and local authorities explained minimal variation in unmet need.

Conclusions Levels of unmet need are high, particularly for support from community services to manage multiple conditions. Patients who could be targeted for support include people who feel socially isolated, and those who have difficulties with their day-to-day living. Younger patients and certain ethnic groups with multimorbidity are also more likely to have unmet needs. Increased personalisation and coordination of care among these groups may help in addressing their needs.

\section{INTRODUCTION}

Over a quarter of adults in England are estimated to have two or more long-term conditions, ${ }^{1}$ referred to as multimorbidity, and this is expected to double between 2015 and 2035. ${ }^{2}$ People with long-term conditions use more health services, accounting for $70 \%$
Strengths and limitations of this study

- Novel analysis of unmet need using primary care data.

- Analysis uses a large national survey with over 750 000 respondents and over 225000 people with multiple long-term conditions.

- This survey is designed to be nationally representative, but it is not designed to be representative of multimorbidity.

- The number of long-term conditions is self-reported and not cross-checked against patients' clinical records.

- Understanding of what 'local services' refer to varies widely among patients, which could compromise the question's validity.

of the total health and social care spend in England. ${ }^{3}$ Prevalence is strongly associated with deprivation: people in deprived areas experience multiple long-term conditions $10-15$ years earlier than in the least deprived areas. $^{4}$

Despite high levels of resource use, qualitative research has documented evidence of unmet need among people with long-term conditions, ${ }^{5}$ describing the lack of personal, social and material resources for multimorbid patients to manage their illnesses, with many patients living isolated lives with little to no support from family, employment or the community-indicating higher levels of unmet need. ${ }^{6}$ From the perspective of resource allocation, unmet need has been defined as 'systematic underutilisation of healthcare resources by particular groups, relative to their level of need'. ${ }^{7}$ A wider definition is 'expressed demand that is suboptimally met', ${ }^{8}$ encompassing receiving poor quality, inadequate or inappropriate care.

Living with long-term conditions has a profound impact on individuals' lives, ${ }^{5}$ and is associated with reduced quality of life ${ }^{9}$ and 
increased mortality. ${ }^{10}$ Patients with multiple conditions experience a significant treatment burden, ${ }^{11}$ and their personal goals for improved care may not align with clinical objectives. Patients' experience of primary care declines with the number of long-term conditions they have. $^{12}$

Primary care services report difficulties in meeting the needs of patients, particularly in deprived areas. ${ }^{13}$ Despite the impact of multimorbidity on individuals and the National Health Service (NHS), general practice (GP) largely operates on a single-disease model. ${ }^{14}$ This may not be appropriate for people with several long-term conditions, for whom meeting disease-specific goals may compromise other aspects of health and well-being. ${ }^{15}$ However, it is difficult for GP to deliver more holistic care for people with multiple long-term conditions due to systemic barriers such as short appointment slots, inadequate clinical guidelines, disorganisation and fragmentation of care and barriers to patient-centred care. ${ }^{16}$

There is no national policy for systematically addressing multimorbidity, although service models to identify people with more complex needs, provide targeted care, and develop broader community support are being promoted. ${ }^{17,18}$ However, there is limited evidence of effectiveness of care coordination or proactive case management, ${ }^{19}$ or for social prescribing, linking patients in primary care to community support, to address social isolation. ${ }^{20-22}$ Furthermore, a large scale randomised controlled study of a best practice approach to care for people with long-term conditions did not find an improvement in quality of life, although the service was valued by patients. ${ }^{23}$

To date, no studies using data from a national patient survey have directly examined unmet need among people with multimorbidity, or sought to investigate the relationship between number of long-term conditions and levels of unmet need in the context of primary care and local services in England. In this paper, we use analysis of the 2018 General Practice Patient Survey (GPPS) ${ }^{24}$ to investigate individual, practice and area level variation in patientreported unmet need, in the context of GP appointments and support from community-based services in England. We address three research questions:

1. What is the relationship between number of long-term conditions and patient-reported unmet need?

2. Among people with multiple long-term conditions, which sociodemographic and health characteristics are associated with unmet need?

3. To what extent do differences between practices or local authorities explain variation in unmet need?

\section{RESEARCH DESIGN AND METHODS}

\section{About the GPPS}

The GPPS is a national survey which provides information about patients' experiences of primary care in England. It was significantly revised in 2018 to include a number of new questions and to extend the age range down to
16. In 2018, 2.2 million questionnaires were sent by post to patients who had been registered with their practice for at least 6 months with a response rate of $34.1 \%{ }^{25}$ The data include weights which can be used to account for non-response bias and unequal selection probabilities. Non-response weights use a model-based approach to estimate the probability of responding based on sociodemographic characteristics of the patient and the neighbourhood in which they live. ${ }^{25}$

\section{Measures of patient needs being met}

We used responses to two questions on patients' views of unmet need:

1. Q30 (all patients): Thinking about the reason for your last general practice appointment, were your needs met?

2. Q38 (patients with at least one long-term condition): In the last 12 months, have you had enough support from local services or organisations to help you manage your condition (or conditions)?

We created a binary outcome variable for each question with the response 'Yes, definitely' interpreted as needs fully met in last appointment or feeling fully supported by local services. Responses 'Yes, to some extent' and 'No, not at all' were interpreted as needs not fully met or not feeling fully supported. Patients who stated that they 'Don't know/can't say' to either question were excluded from the analysis. The response to question 38 'I haven't needed support' was also excluded.

\section{Demographic and health characteristics}

Patients were asked to report whether they had at least one of 16 categories of long-term conditions. This was used to create the long-term condition count used in the analysis with patients with five or more long-term conditions combined. Age was measured using eight bands from 16 to 24 to $85+$ years. The ethnicity categories reflect those in the 2011 Census from the Office of National Statistics. The Index of Multiple Deprivation (2015) was used as a patient-level characteristic, based on patients' lower layer super output area of residence. These areas were ranked from 1 (most deprived area) to 32844 (least deprived area) and grouped into quintiles of decreasing levels of deprivation.

We looked at the complexity of patients' needs by including measures of frailty. The question asks patients whether they have experienced any of the following in the last 12 months: problems with physical mobility; two or more falls requiring medical attention; and feeling isolated from others. We additionally considered whether patients' ability to carry out activities of daily living might relate to feeling their needs were met.

\section{Practice characteristics}

We created a practice level categorical variable for size of practice, ranked 1-7 to cover the following numbers of registered patients: 1-1999; 2000-3999; 4000-5999; 6000-7999; 8000-9999; $10000-14999$ and 15000 or more. 
Table 1 Needs fully met among patients with single and multiple long-term conditions

\begin{tabular}{|c|c|c|c|c|c|c|}
\hline & $\begin{array}{l}\text { Single long- } \\
\text { term condition } \\
(n=90364)\end{array}$ & $\begin{array}{l}\text { Two long-term } \\
\text { conditions } \\
\text { ( } n=54047)\end{array}$ & $\begin{array}{l}\text { Three } \\
\text { long-term } \\
\text { conditions } \\
(n=30 \text { 162) }\end{array}$ & $\begin{array}{l}\text { Four } \\
\text { long-term } \\
\text { conditions } \\
(n=14561) \\
\end{array}$ & $\begin{array}{l}\text { Five or more } \\
\text { long-term } \\
\text { conditions } \\
(n=10016)\end{array}$ & $\begin{array}{l}\text { Total } \\
(n=199150)\end{array}$ \\
\hline $\begin{array}{l}\text { Needs fully met in last GP } \\
\text { appointment } n(\%)\end{array}$ & 61659 (64.0) & 36661 (64.4) & $20074(63.4)$ & 9455 (63.0) & $6281(60.8)$ & $134130(63.8)$ \\
\hline $\begin{array}{l}\text { Feeling fully supported by } \\
\text { local services } n(\%)\end{array}$ & 48725 (48.4) & 26615 (44.5) & $13120(39.4)$ & 5606 (35.9) & 3347 (31.2) & 97413 (44.8) \\
\hline
\end{tabular}

GP, general practice.

\section{Analyses}

We ran three series of models for the analysis. Two sets of models included patients with at least one longterm condition who had a valid response to question 30 and a valid response to question 38. The first series looked at whether patients' needs were met in their last GP appointment. For the second group of models, we looked at how supported by local services patients feel in managing their conditions. The third group used a smaller sample limited to patients with two or more conditions to assess the likelihood of needs being fully met across different patient characteristics.

We looked at the unadjusted relationships between the outcome questions and sociodemographic factors, health status and practice size with multilevel logistic regression models including a random effect for practice. We also produced multilevel logistic regression models adjusting for sociodemographics, health status and practice size to analyse the relationship between number of long-term conditions and unmet need. For the question regarding support from local services, we added local authority as another random effect to the model to create a third level.

We used the intraclass correlation coefficients to determine whether area-level variation remained after controlling for all other patient characteristics. We also compared the coefficient from our final mixed effects models to fixed effects models excluding the random effect for practice or local authority to establish how much of the variation was due to certain groups being concentrated in particular practices or areas.

For each characteristic, we subtracted the within-practice odds from the overall odds to calculate the between-practice effects. These estimates reflected differences in unmet need that were attributable to between-practice effects. For instance, if patients with five or more long-term conditions reported higher odds of needs met compared with those with a single condition, within practices rather than overall, then this shows that the multimorbid group is registered with practices that have (on average) lower levels of fully met need.

All logistic regression results were presented as ORs with $95 \%$ CIs and significance measured at the $5 \%$ level. Analyses were conducted with SAS V.9.4.

\section{Sensitivity analyses}

We compared the main results for models testing whether patients' needs were met in their last appointment by extending the size of the sample to include those who did not report having any long-term conditions. We ran a model adjusting for sociodemographic and practice characteristics.

\section{Patient and public involvement statement}

Patients were not involved in the development or design of the research. Preliminary results from this study were shared with the Taskforce on Multiple Conditions-a cross-sector partnership between the Richmond Group for Charities, The Royal College of GPs and Guy's and St Thomas' Charity.

\section{RESULTS}

From the 758165 returned questionnaires, 709742 responded to the needs met in last appointment question and 423164 responded to the feeling supported by local services outcome. After excluding those with missing or invalid responses to these outcomes or other sociodemographic and health status variables, we had a sample of 199 150 responses. These patients were also from practices with at least 30 survey responses. Further details on these exclusions can be found in online supplemental appendix 1.

Of the sample of 199150 patients, $63.8 \%$ felt that their needs were met in their last appointment and $44.8 \%$ felt that they were fully supported by local services (see table 1). These proportions were higher for both measures for those with a single condition $(64.0 \%$ and $48.4 \%$, respectively) and lower for patients with five or more conditions $(60.8 \%$ and $31.2 \%$, respectively).

We also looked at the distribution of patient and health characteristics by varying numbers of long-term conditions (table 2). Patients with increasing levels of multimorbidity were older, reported more complex health needs (higher proportions reporting issues with frailty and difficulties activities of with daily living) and had a lower proportion of people in full-time or part-time employment $(6.8 \%)$, compared with those with a single long-term condition $(60.6 \%)$. While the proportions of people with a single condition were similar between the most and least deprived quintiles, the highest level 


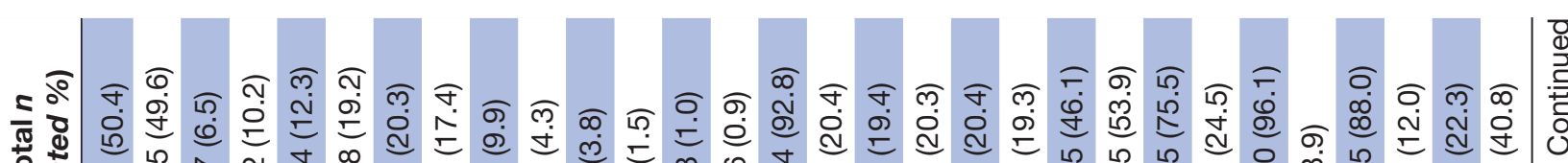
† उ.

\section{×}

\%

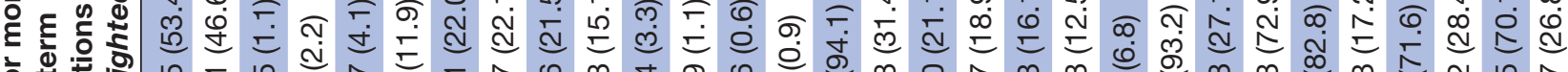
tᄒ

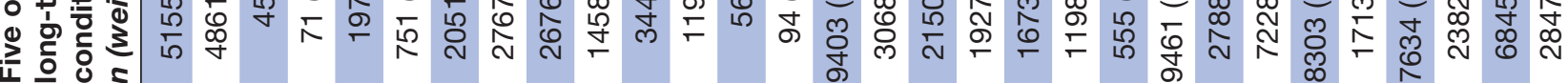

E $\widehat{\circ}$

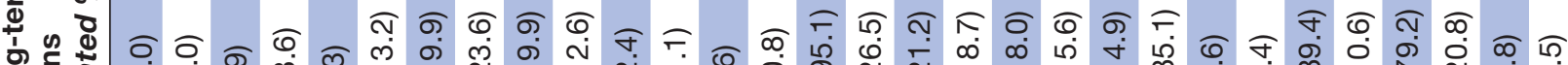

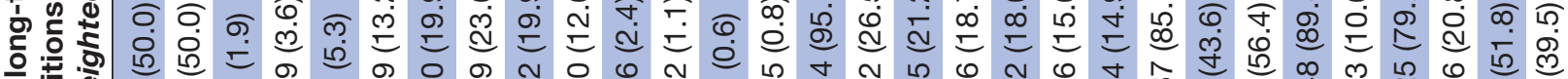

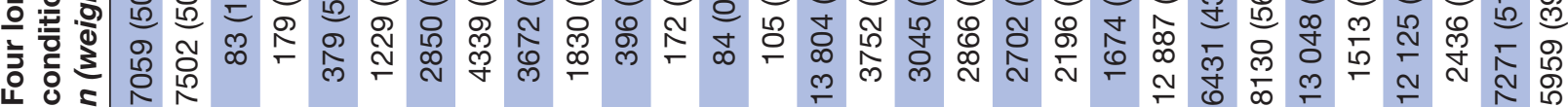

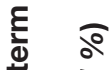

क̆ ó

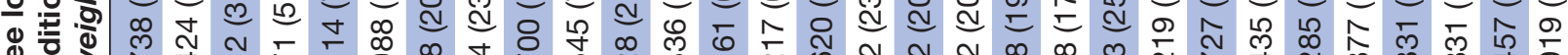

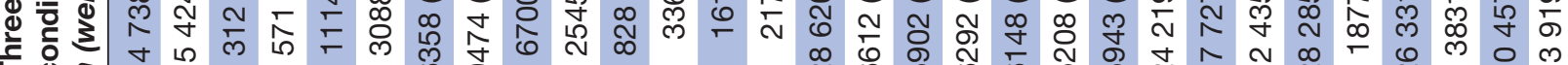

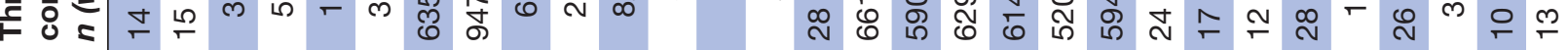

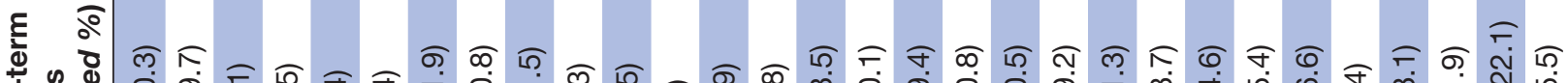
光

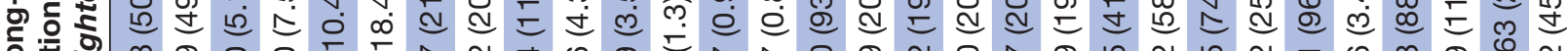

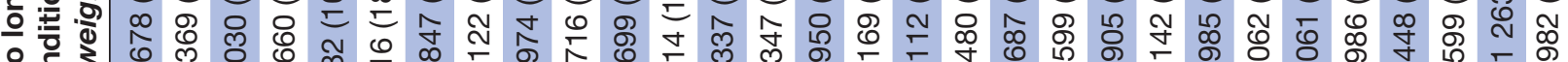

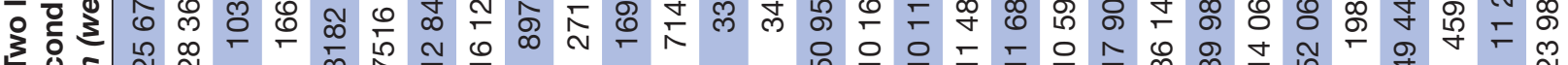

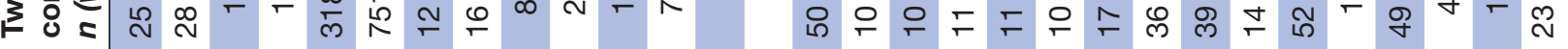

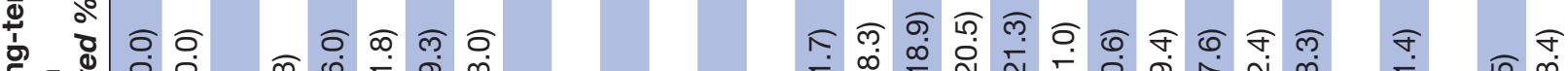

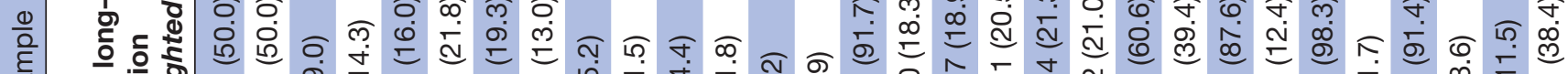

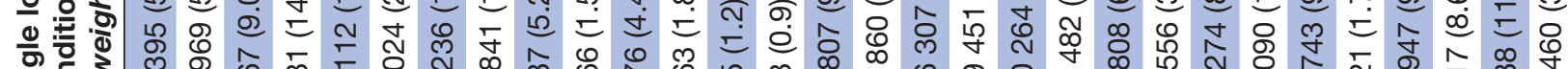

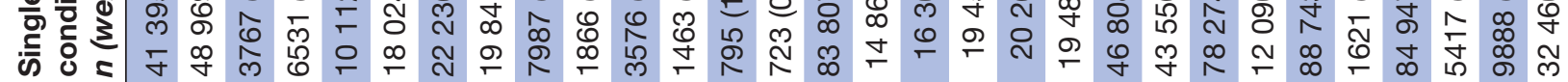

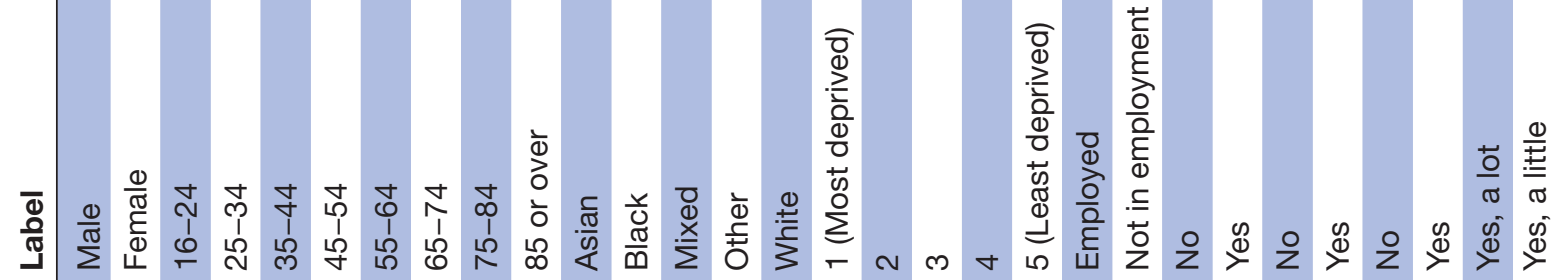




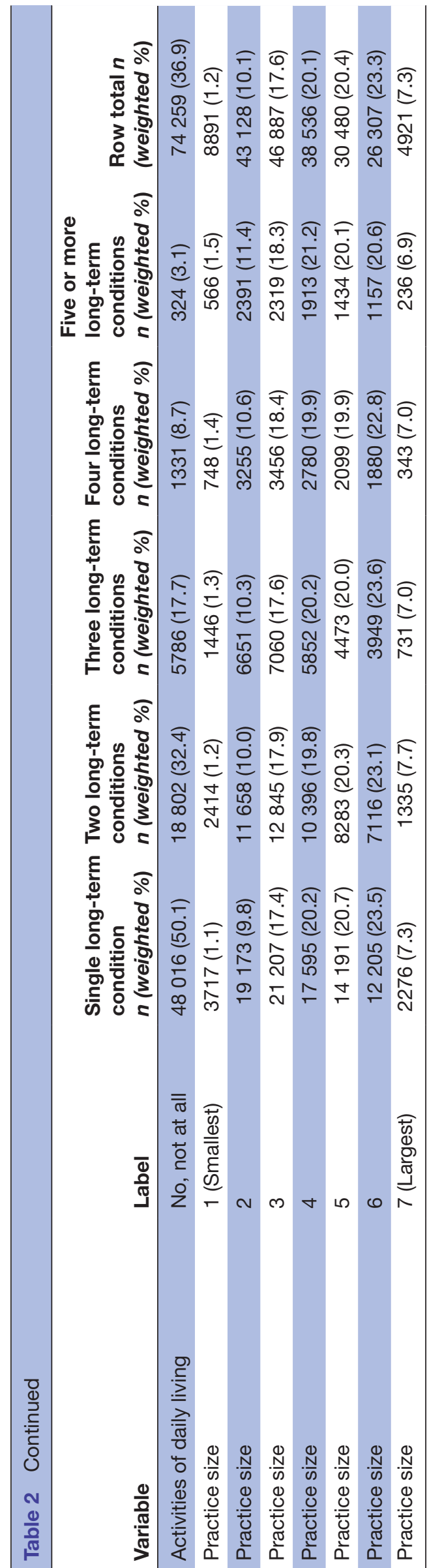

of multimorbidity was more common in those living in the most deprived areas compared with the least deprived (31.4\% and $12.5 \%$, respectively).

Does the number of conditions a patient has relate to whether their needs are met in the last appointment, and whether they feel supported by local services?

Patients with the highest level of multimorbidity (those with five or more long-term conditions) were least likely to report that their needs were fully met in their last GP appointment (OR=0.80, 95\% CI 0.76 to 0.83 ) compared with those with a single condition. After adjusting for sociodemographic factors, there was a clearer additive relationship between multimorbidity and patients' needs being met, with those reporting five or more long-term conditions having the lowest likelihood relative to those with one long-term condition $(\mathrm{OR}=0.63,95 \% \mathrm{CI} 0.60$ to $0.66)$. When additionally adjusting for frailty and activities of daily living, there was no significant difference in the likelihood of having needs met between those with multiple long-term conditions versus patients with a single long-term condition ( $\mathrm{OR}=1.04,95 \%$ CI 0.99 to 1.09 ).

An increase in the number of comorbid conditions was associated with a lower likelihood of feeling supported by local services. When comparing patients with a single condition, those with five or more long-term conditions were the least likely to feel supported ( $\mathrm{OR}=0.45,95 \%$ CI 0.43 to 0.47 ). After adjusting for sociodemographic factors, patients with the highest level of multimorbidity were least likely to report feeling supported by local services, compared with those with a single long-term condition (OR=0.35, $95 \%$ CI 0.33 to 0.36$)$. The relationship with increasing number of long-term conditions and lower likelihood of feeling supported held after adjustment for frailty and activities of daily living $(\mathrm{OR}=0.84$, $95 \%$ CI 0.80 to 0.88 ) (see figure 1 and online supplemental appendix 2-3 for full results).

Is there is an effect related to the patients' practice or local authority, and if so, what is the size of this effect?

After controlling for sociodemographic and health characteristics, we explored area-level effects using the intraclass correlation coefficients. We found variation at the practice level accounted for a statistically significant portion of the variation in patient-reported unmet need, though the size of this effect was small $(2.7 \%)$. The same was also true in explaining variation relating to how supported patients felt by local services in managing their condition(s), with local authority and practice level areas accounting for $0.6 \%$ and $1.3 \%$ of the variation, respectively.

There was still a difference by number of long-term conditions in the odds of feeling supported by local services after adjustment, so we looked to see if patients with five or more conditions felt less supported because they were more likely to attend practices in local authorities with overall lower odds of patients feeling supported. However, this accounted for just 2.7\% of the overall mean difference between patients with no and high 
(1) Needs met in most recent GP appointment (ref=1 LTC, $n=199,150)$

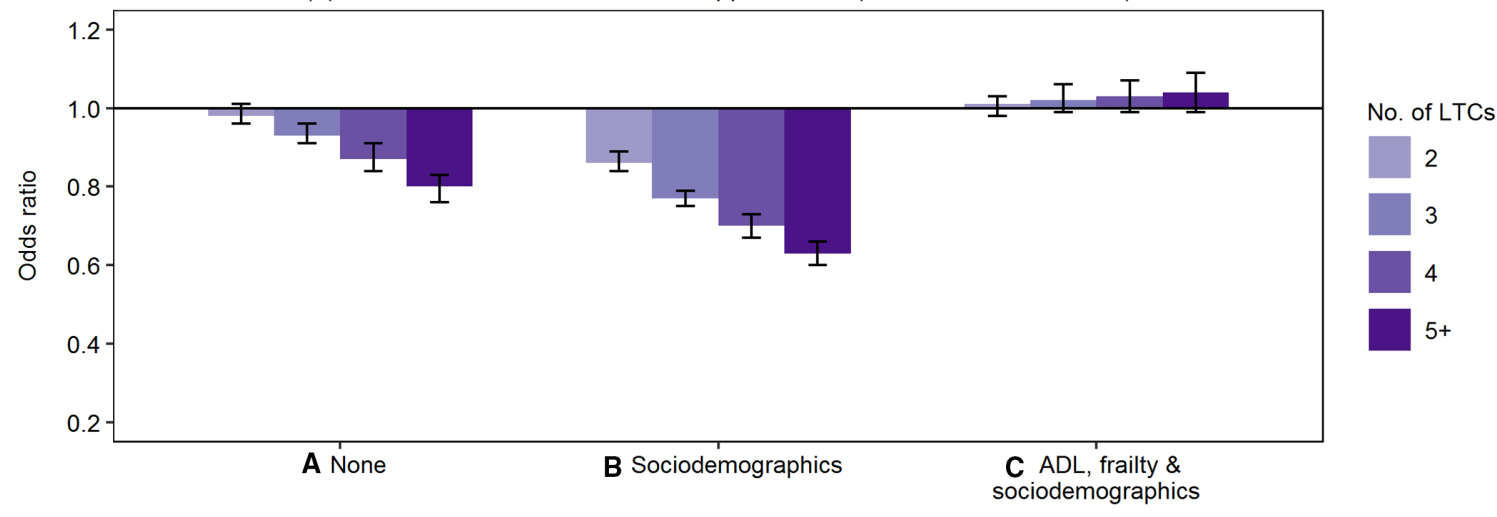

(2) Feeling fully supported by local services (ref=1 LTC, $n=199,150$ )

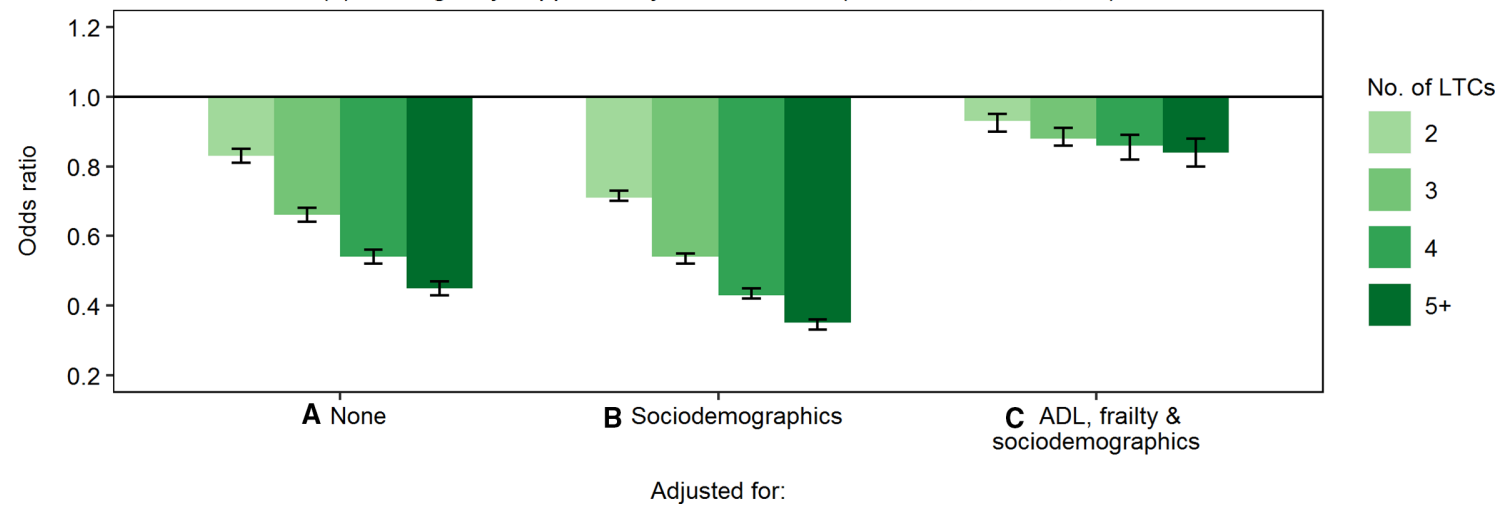

Figure 1 Relationship between number of long-term conditionsand whether patients' needs were met in either general practice (1) or through local services. (2) Models were unadjusted (A); adjusted for sociodemographic factors (B); and further adjusted for frailty and activities of daily living (C). GP, general practice. LTC, long-term condition. ADL, activities of daily living.

multimorbidity. The full results are presented in online supplemental appendix 4-6.

\section{Which sociodemographic and health characteristics in those with multiple long-term conditions are associated with differences in unmet need?}

Of our sample of 199150 patients, 108786 reported having two or more long-term conditions. When controlling for sociodemographic and health characteristics, patients who experienced aspects of frailty were less likely to report that their needs were fully met in their last appointment compared with their non-frail counterparts; the largest effect was for patients experiencing isolation $(\mathrm{OR}=0.51$, $95 \%$ CI 0.49 to 0.53 ). Those who had difficulty in carrying out activities of daily living were also less likely to have their needs fully met in their last appointment compared with those who expressed no difficulties $(\mathrm{OR}=0.53,95 \%$ CI 0.51 to 0.56 ). This was also the case for support from local services, where those who expressed a lot of difficulties were less likely to feel supported (OR=0.26, 95\% CI 0.24 to 0.28$)$.

There were large differences in unmet need by ethnicity, with Asian patients least likely to report their needs being met in their last appointment compared with white patients $(\mathrm{OR}=0.59,95 \% \mathrm{CI} 0.55$ to 0.64$)$. This was also the case when looking at the likelihood of Asian patients feeling supported by local services $(\mathrm{OR}=0.52$, $95 \%$ CI 0.46 to 0.59$)$.
There were also differences in unmet need by age. Those aged 85 and above were more likely to report their needs being fully met in their last appointment $(\mathrm{OR}=1.35$, 95\% CI 1.27 to 1.44 ) and by local services (OR=1.65, 95\% CI 1.51 to 1.81$)$ compared with adults aged $45-54$. The youngest age group (16-24 year old) were least likely to report having their needs fully met in GP $(\mathrm{OR}=0.66$, $95 \%$ CI 0.59 to 0.74$)$ and felt the least supported by local services $(\mathrm{OR}=0.58,95 \% \mathrm{CI} 0.45$ to 0.75$)$. The full results are presented in table 3.

\section{Sensitivity analyses}

Including patients with no long-term conditions increased the size of the sample to 657169 . Those with five or more conditions were least likely to feel that their needs were fully met in their last appointment compared with those with a single condition which was consistent with our main findings ( $\mathrm{OR}=0.65,95 \%$ CI 0.62 to 0.67$)$. Those with no longterm conditions were most likely to report their needs being fully met $(\mathrm{OR}=1.10,95 \%$ CI 1.08 to 1.11$)$.

\section{DISCUSSION}

\section{Main findings}

Over a third of patients do not feel that their needs were fully met in last GP practice appointment and 
Table 3 Differences in unmet need by sociodemographic and health characteristics of patients with multiple long-term conditions $(n=108786)$

\begin{tabular}{|c|c|c|c|c|}
\hline Variable & Category & $\begin{array}{l}\text { Needs met in last GP } \\
\text { appointment }\end{array}$ & $\begin{array}{l}\text { Feeling fully supported by } \\
\text { local services }\end{array}$ & Frequency $n$ \\
\hline & & Adjusted ORs & & \\
\hline Activities of daily living & No, not at all & Ref & Ref & 26243 \\
\hline Activities of daily living & Yes, a lot & $0.53^{*}(0.51,0.56)$ & $0.26^{\star}(0.24,0.28)$ & 35836 \\
\hline Activities of daily living & Yes, a little & $0.56^{\star}(0.54,0.58)$ & $0.36^{\star}(0.34,0.38)$ & 46707 \\
\hline Frailty (isolation) & No & Ref & Ref & 95538 \\
\hline Frailty (isolation) & Yes & $0.51^{\star}(0.49,0.53)$ & $0.42^{\star}(0.40,0.45)$ & 13248 \\
\hline Frailty (mobility) & No & Ref & Ref & 66931 \\
\hline Frailty (mobility) & Yes & $0.85^{\star}(0.83,0.88)$ & $0.76^{\star}(0.73,0.80)$ & 41855 \\
\hline Frailty (falls) & No & Ref & Ref & 101697 \\
\hline Frailty (falls) & Yes & $0.85^{\star}(0.81,0.90)$ & $1.02(0.95,1.09)$ & 7089 \\
\hline Age band & $45-54$ & Ref & Ref & 12584 \\
\hline Age band & $16-24$ & $0.66^{\star}(0.59,0.74)$ & $0.58^{\star}(0.45,0.75)$ & 1470 \\
\hline Age band & $25-34$ & $0.87^{\star}(0.79,0.95)$ & $0.77^{\star}(0.64,0.93)$ & 2481 \\
\hline Age band & $35-44$ & $0.90^{\star}(0.84,0.97)$ & $0.92(0.81,1.05)$ & 4872 \\
\hline Age band & $55-64$ & $1.08^{*}(1.03,1.13)$ & $1.15^{\star}(1.07,1.25)$ & 24106 \\
\hline Age band & $65-74$ & $1.17^{*}(1.11,1.22)$ & $1.43^{\star}(1.33,1.55)$ & 32702 \\
\hline Age band & $75-84$ & $1.23^{*}(1.17,1.30)$ & $1.55^{\star}(1.43,1.68)$ & 22022 \\
\hline Age band & 85 or over & $1.35^{\star}(1.27,1.44)$ & $1.65^{\star}(1.51,1.81)$ & 8549 \\
\hline Ethnicity & White & Ref & Ref & 102777 \\
\hline Ethnicity & Asian & $0.59^{\star}(0.55,0.64)$ & $0.52^{*}(0.46,0.59)$ & 3267 \\
\hline Ethnicity & Black & $0.77^{*}(0.68,0.86)$ & $0.54^{\star}(0.45,0.66)$ & 1341 \\
\hline Ethnicity & Mixed & $0.88(0.75,1.04)$ & $1.05(0.81,1.36)$ & 638 \\
\hline Ethnicity & Other & $0.71^{\star}(0.61,0.82)$ & $0.65^{\star}(0.52,0.81)$ & 763 \\
\hline Deprivation quintile & 5 (Least deprived) & Ref & Ref & 19201 \\
\hline Deprivation quintile & 1 (Most deprived) & $0.94^{*}(0.90,0.98)$ & $0.89^{*}(0.84,0.95)$ & 23601 \\
\hline Deprivation quintile & 2 & $0.95^{\star}(0.91,0.99)$ & $0.92^{\star}(0.87,0.98)$ & 21209 \\
\hline Deprivation quintile & 3 & $1.02(0.97,1.06)$ & $0.95(0.89,1.01)$ & 22565 \\
\hline Deprivation quintile & 4 & $1.01(0.97,1.06)$ & $1.01(0.95,1.08)$ & 22210 \\
\hline Employment status & Employed & Ref & Ref & 26077 \\
\hline Employment status & Not in employment & $1.36^{\star}(1.31,1.41)$ & $1.14^{*}(1.07,1.21)$ & 82709 \\
\hline Gender & Male & Ref & Ref & 52630 \\
\hline Gender & Female & $0.97^{\star}(0.94,0.99)$ & $0.86^{\star}(0.83,0.89)$ & 56156 \\
\hline Practice size & 1 (Smallest) & Ref & Ref & 5174 \\
\hline Practice size & 2 & $0.95(0.87,1.02)$ & $0.92(0.84,1.01)$ & 23955 \\
\hline Practice size & 3 & $0.89^{*}(0.82,0.96)$ & $0.87^{\star}(0.79,0.95)$ & 25680 \\
\hline Practice size & 4 & $0.85^{\star}(0.78,0.92)$ & $0.78^{\star}(0.71,0.86)$ & 20941 \\
\hline Practice size & 5 & $0.81^{*}(0.75,0.88)$ & $0.80 *(0.72,0.88)$ & 16289 \\
\hline Practice size & 6 & $0.78^{\star}(0.72,0.85)$ & $0.74^{*}(0.67,0.82)$ & 14102 \\
\hline Practice size & 7 (Largest) & $0.71^{\star}(0.63,0.80)$ & $0.69^{*}(0.60,0.81)$ & 2645 \\
\hline
\end{tabular}

GP, general practice.

approximately one in two patients with long-term health conditions do not feel supported by local services.

Unmet need is higher among people with a greater number of long-term health conditions. We observed a dose-response effect that persists even when controlling for sociodemographic characteristics, and is stronger for unmet need relating to local services compared with unmet need within GP appointments. 
Patients' health status accounted for a large part of the variation in whether patients felt their needs were met. Accounting for complexity in the model removed differences in needs met in the last appointment based on number of conditions, and reduced the differences by number of conditions for local services.

Our analysis identified groups of patients with multimorbidity more likely to have unmet needs, for whom targeted interventions could be prioritised: most nonWhite patient groups, those who are frail and patients reporting difficulties carrying out activities of daily living. We also found that those younger than 45 years old were more likely to have unmet needs. Differences in ethnicity and age reported in our study supports previous research, which found less positive primary care experiences for patients in these groups. ${ }^{26}$

We found that variation between either GP practices or local authorities accounts for minimal variation in whether patients' needs are met, either in the last appointment or from local services. Unmet need varied by practice size in all models; with patients from larger practices less likely to report having their needs fully met.

\section{Comparison with previous studies}

No previous studies have examined unmet need using the GPPS, though previous research has found that patients' experience of primary care declines with an increasing number of conditions. ${ }^{12}$ That being said, previous analysis of the Canadian Community Health Survey has highlighted the association between long-term conditions and unmet need, with the likelihood of reporting unmet need increasing as the number of long-term conditions increases. ${ }^{27} \mathrm{~A}$ further example of international literature into unmet need found that American patients with significant chronic illness burden were less likely to report that they got what they needed from their primary care professional. ${ }^{28}$

Strengths of our research include a large sample size and using data from a national survey comprising longstanding validated questions, which have been subject to cognitive testing. A further strength is that this was a novel analysis of primary care data on unmet need, and adds to a landscape of literature on what is already known.

Although the overall sample size was large, one limitation of our study is that numbers of patients being analysed within certain subgroups were quite small. The overall response rate was $34 \%$, so some patient groups may be more represented than others-while the survey is nationally representative, it is not designed to be representative of multimorbidity across the country. Another limitation is that the number of long-term conditions was self-reported by patients in the survey which is not cross-checked against patients' clinical records. A further limitation is interpretation of the survey questions by patients; in particular, the question relating to support from local services. Feedback from cognitive testing indicates that the understanding of what 'local services' refers to varies widely among patients. It ranges from relatives working within healthcare, to condition-specific support groups, to social care-services which are funded through various means and do not fall under the remit of a single organisation. This makes it challenging to make direct recommendations to organisations planning for financial resource allocation. A further challenge is that availability of such services varies across the country, and the extent of this variation is difficult to quantify. We cannot be sure from our findings whether unmet need is populationdriven (patients not accessing available services) or service-driven (particular services not being available in the area). As well as this, there are different ways in which to measure unmet need, with our study being one such example.

\section{Implications for policy and clinical practice}

Our analyses show a high level of unmet need reported by patients attending services in the community; this includes local services and organisations and, to a lesser extent, appointments in primary care. We found that patients with multimorbidity are more likely to have unmet needs than those with a single condition. The level of unmet need is concerning, particularly given the primary care policy focus on improving access. Longer appointment times for patients with complex needs, and practice workflow that supports relational continuity are recommended to improve care of people with multimorbidity. ${ }^{29}$ However, both are more challenging to deliver alongside improving access and delivering primary care at scale. ${ }^{30}$ Improving equity of access risks increasing inequalities in quality of care.

A further question raised by the level of unmet need is the impact on service use in both primary and secondary care: what do patients do when their needs are not being met? Further GP and hospital visits may be occurring due to unmet needs or awareness of support available, contributing to the higher hospital admission rates of people with more long-term conditions. ${ }^{31}$

We found that whether people with long-term conditions feel their needs are met is closely related to complexity of patient need. This emphasises the need for person-centred care, a finding which is consistent with previous studies. ${ }^{23}$ As the NHS works to deliver more personalised care for people with complex needs, particularly in deprived areas, it will be important to track the impact on patients with multimorbidity. Unmet need resulting from patients not being aware of what services are available could be addressed more rapidly through personalised care programmes.

Our analysis did not find material area effects of individual GP practices or local authorities, which we thought might explain a large part of variation in unmet need. Rather, we found that individual patient characteristics and the complexity of their health needs were the dominant factors. In policy terms, this emphasises the importance of addressing antecedents of multiple long-term conditions, and ensuring that resource allocation takes account of the higher needs in deprived populations 
where prevalence of multimorbidity is greatest. The lack of an area effect is an unexpected finding, which goes against the grain of some current thinking that higher levels of need are likely to be associated with reduced 'community resilience'. ${ }^{19}$ With that said, we suggest that signposting across local areas could be improved to direct people to available services between primary care and the voluntary sector.

\section{Implications for further research}

Future research could look further into whether there are specific long-term conditions, or combinations of conditions, that are associated with unmet need in GP or local services. For instance, there may be conditions that are more prevalent in younger age groups which could further unpick the age effect in unmet need.

Additional area effects which could be explored are the ratio of GPs to patients in each practice, rather than practice size alone. There is also potential to analyse differences in unmet need when accounting for rurality, particularly as variation in healthcare delivery between urban and rural areas may impact the extent to which primary care and other local services focus on patients with multimorbidity.

We would recommend taking account of whether personalisation initiatives have any impact on unmet need in people with multimorbidity, and whether such solutions benefit from strong relationships between healthcare providers, the voluntary sector and the community. Further research looking at variation in unmet need could also extend to looking at the relationship of continuity in primary care for improving the experience of patients with long-term conditions, and whether continuity contributes to patients' confidence in self-management.

While models of care are largely based on single diseases, it is evident that multimorbidity is increasingly becoming the norm and there is a need for a more generalist approach to complement this. Clinicians, policy makers and charities are encouraged to take account of increasing support for those with multiple long-term conditions, through increased coordination and personalisation of care, while maintaining a balance of providing the same quality of care to all patients. This approach should be considered for particular groups of patients who are more likely to experience unmet need, including those experiencing high levels of isolation and difficulties in day-to-day living.

Twitter Lucina Rolewicz @LucinaRolewicz, Eilís Keeble @eiliskeeble, Charlotte Paddison@CAM_Paddison and Sarah Scobie @SarahScobie2

Contributors LR, EK and SS drafted the initial paper and had full access to all of the data in the study and take responsibility for the integrity of the data and accuracy of the data analysis. SS conceived the initial research questions. CP conducted a literature review into previous studies on multimorbidity and unmet need. LR, EK, CP and SS reviewed/edited the manuscript, refined the research questions and contributed to discussion; contributed to the revision of the paper, approved the final version of the manuscript and agreed to be accountable for all aspects of the work. LR and EK completed the statistical analysis.

Funding The authors have not declared a specific grant for this research from any funding agency in the public, commercial or not-for-profit sectors.
Competing interests None declared.

Patient consent for publication Not required.

Provenance and peer review Not commissioned; externally peer reviewed.

Data availability statement Data may be obtained from a third party and are not publicly available. Patient-level General Practice Patient Survey (GPPS) data are pseudonymised and non-identifiable. Data were shared under a Data Sharing Agreement between the Disclosing Data Controller (NHS England) and the Receiving Data Controller (Nuffield Trust). This agreement covers the use of these data for this analysis only and cannot be processed for any other purpose. The data can be requested through NHS England's Insight Team at england.insight-queries@nhs.net.

Supplemental material This content has been supplied by the author(s). It has not been vetted by BMJ Publishing Group Limited (BMJ) and may not have been peer-reviewed. Any opinions or recommendations discussed are solely those of the author(s) and are not endorsed by BMJ. BMJ disclaims all liability and responsibility arising from any reliance placed on the content. Where the content includes any translated material, BMJ does not warrant the accuracy and reliability of the translations (including but not limited to local regulations, clinical guidelines, terminology, drug names and drug dosages), and is not responsible for any error and/or omissions arising from translation and adaptation or otherwise.

Open access This is an open access article distributed in accordance with the Creative Commons Attribution Non Commercial (CC BY-NC 4.0) license, which permits others to distribute, remix, adapt, build upon this work non-commercially, and license their derivative works on different terms, provided the original work is properly cited, appropriate credit is given, any changes made indicated, and the use is non-commercial. See: http://creativecommons.org/licenses/by-nc/4.0/.

\section{ORCID iDs}

Lucina Rolewicz http://orcid.org/0000-0003-4308-2408

Eilís Keeble http://orcid.org/0000-0002-7932-1901

Charlotte Paddison http://orcid.org/0000-0003-0184-9666

Sarah Scobie http://orcid.org/0000-0003-0956-5158

\section{REFERENCES}

1 Cassell A, Edwards D, Harshfield A, et al. The epidemiology of multimorbidity in primary care: a retrospective cohort study. Br J Gen Pract 2018;68:e245-51.

2 Kingston A, Robinson L, Booth $\mathrm{H}$, et al. Projections of multimorbidity in the older population in England to 2035: estimates from the population ageing and care simulation (PACSim) model. Age Ageing 2018;47:374-80. -

3 Department of Health. Long term conditions compendium of information. Leeds, UK: DH, 2012. https://www.gov.uk/government/ uploads/system/uploads/attachment_data/file/216528/dh_134486. pdf. (accessed February 2020).

4 Barnett K, Mercer SW, Norbury M, et al. Epidemiology of multimorbidity and implications for health care, research, and medical education: a cross-sectional study. The Lancet 2012;380:37-43.

5 Richmond Group of Charities. "Just one thing after another" Living with multiple conditions - A report from the Taskforce on Multiple Conditions 2018. Available: https://richmondgroupofcharities.org. uk/sites/default/files/final_just_one_thing_after_another_report_-singles.pdf [Accessed February 2020].

6 O'Brien R, Wyke S, Guthrie B, et al. An 'endless struggle': a qualitative study of general practitioners' and practice nurses' experiences of managing multimorbidity in socio-economically deprived areas of Scotland. Chronic IIIn 2011;7:45-59.

7 Aragon Aragon MJM, Chalkley MJ, Goddard MK. Defining and measuring unmet need to guide healthcare funding: identifying and filling the gaps. York: Centre for Health Economics, University of York, 2017: 8.

8 The Academy of Medical Sciences. Unmet need in healthcare 2017. Available: https://acmedsci.ac.uk/file-download/430378 [Accessed February 2020].

9 Mujica-Mota RE, Roberts M, Abel G, et al. Common patterns of morbidity and multi-morbidity and their impact on health-related quality of life: evidence from a national survey. Qual Life Res 2015;24:909-18. -

10 DuGoff EH, Canudas-Romo V, Buttorff C, et al. Multiple chronic conditions and life expectancy: a life table analysis. Med Care 2014;52:688-94.

11 Dobler CC, Harb N, Maguire CA, et al. Treatment burden should be included in clinical practice guidelines. BMJ 2018:363. 
12 Paddison CAM, Saunders CL, Abel GA, et al. Why do patients with multimorbidity in England report worse experiences in primary care? Evidence from the general practice patient survey. BMJ Open 2015;5:e006172.

13 Mercer SW, Guthrie B, Furler J, et al. Multimorbidity and the inverse care law in primary care. BMJ 2012;344:e4152.

14 Mercer SW, Salisbury C. Multimorbidity and the primary care clinic, 2017. Available: https://basicmedicalkey.com/multimorbidity-andthe-primary-care-clinic/ [Accessed February 2020].

15 National Institute for Health and Care Excellence. Multimorbidity Quality Standard [QS153], 2017. Available: https://www.nice.org.uk/ guidance/qs153 [Accessed February 2020].

16 Sinnott C, Mc Hugh S, Browne J, et al. GPs' perspectives on the management of patients with multimorbidity: systematic review and synthesis of qualitative research. BMJ Open 2013;3:e003610.

17 NHS England. Universal personalised care, 2019. Available: https:// www.england.nhs.uk/personalisedcare/upc/ [Accessed February 2020].

18 Richmond Group of Charities. The multiple conditions guidebook - a report from the Taskforce on multiple conditions, 2019. Available: https://richmondgroupofcharities.org.uk/sites/default/files/multiple_ conditions_report_a4_digital.pdf [Accessed February 2020].

19 Imison C, Curry N, Holder H, et al. Shifting the balance of care: great expectations. research report, Nuffield trust 2017. Available: https:// www.nuffieldtrust.org.uk/files/2017-02/shifting-the-balance-of-carereport-web-final.pdf [Accessed February 2020].

20 Bickerdike L, Booth A, Wilson PM, et al. Social prescribing: less rhetoric and more reality. A systematic review of the evidence. BMJ Open 2017;7:e013384.

21 Chatterjee HJ, Camic PM, Lockyer B, et al. Non-Clinical community interventions: a systematised review of social prescribing schemes. Arts Health 2018;10:97-123.

22 Mercer SW, Fitzpatrick B, Grant L, et al. Effectiveness of CommunityLinks practitioners in areas of high socioeconomic deprivation. Ann Fam Med 2019;17:518-25.
23 Salisbury C, Man M-S, Bower P, et al. Management of multimorbidity using a patient-centred care model: a pragmatic cluster-randomised trial of the 3D approach. The Lancet 2018;392:41-50.

24 GP Patient Survey. GP Patient Survey - Questionnaire redevelopment, 2018. Available: https://www.gp-patient.co.uk/Files/ GPPS\%20Y12\%20Questionnaire\%20redevelopment\%20report\% 20v1\%20PUBLIC.pdf [Accessed March 2020].

25 GP Patient Survey. GP Patient Survey - Technical Annex, 2018. Available: https://www.gp-patient.co.uk/downloads/archive/2018/ GPPS\%202018\%20Technical\%20Annex\%20PUBLIC.pdf [Accessed March 2020].

26 Lyratzopoulos G, Elliott M, Barbiere JM, et al. Understanding ethnic and other socio-demographic differences in patient experience of primary care: evidence from the English general practice patient survey. BMJ Qual Saf 2012;21:21-9.

27 Ronksley PE, Sanmartin C, Quan H, et al. Association between chronic conditions and perceived unmet health care needs. Open Med 2012;6:48-58.

28 Cunningham A, Mautner D, Ku B, et al. Frequent emergency department visitors are frequent primary care visitors and report unmet primary care needs. J Eval Clin Pract 2017;23:567-73.

29 Wallace E, Salisbury C, Guthrie B, et al. Managing patients with multimorbidity in primary care. BMJ 2015;350:h176.

30 Palmer W, Hemmings N, Rosen R, et al. Improving access and continuity in general practice. research report, Nuffield trust 2018. Available: https://www.nuffieldtrust.org.uk/files/2019-01/improvingaccess-and-continuity-in-general-practice-evidence-review-finalupdate-01-2019.pdf [Accessed March 2020].

31 Stafford M, Steventon A, Thorlby R, et al. Understanding the health care needs of people with multiple health conditions. The health Foundation 2018. Available: https://www.health.org.uk/sites/default/ files/upload/publications/2018/Understanding\%20the\%20health\% 20care\%20needs\%20of\%20people\%20with\%20multiple\% 20health\%20conditions.pdf [Accessed April 2020]. 